\title{
Students' Motivation to Learn in Primary School
}

\author{
Ivana Bojović \\ ORCID: 00oo-0001-7260-0927 • ResearcherID: V-9215-2017 \\ Medical School, Užice \\ Radovan Antonijević \\ ORCID: 00oo-0003-4959-376X • ResearcherID: M-2929-2017 \\ University of Belgrade, Faculty of Philosophy
}

Received 1 December 2017 • Revised $252017 \cdot$ Accepted 28 December 2017

\section{Abstract}

\begin{abstract}
The paper presents considerations about the characteristics of students' motivation in primary school and how students view certain characteristics of the teaching process as motivating or demotivating. The research included fifth and eighth graders, 617 students from ten primary schools in Serbia. We assumed that primary school students are partially motivated to learn. The results lead us to conclude that the students believe they can achieve their goals by self-efficacy. They have the high level of self-perception of competences. Self-worth, i.e. students' views of their own qualities, is least valued. The results show the high level of value of academic achievements. Social goals are also important to students. Nonconformity is not satisfactorily developed. The gender, grade and school achievement differences in students' motivation to learn. The results show that not all teaching strategies are equally motivating. A large percentage of students are indifferent to certain teaching strategies.
\end{abstract}

Keywords: primary school, motivation to learn, teaching strategies.

\section{Introduction}

Individuals are often faced with the question of motivation, both, own and of others, in different activities and fields of their functioning. One of targets for researches within the field of education is to find out, as efficient as possible, strategies to motivate students to learn and to improve effects of learning. Efficient learning does not depend only on methods and forms of work in teaching process, but on feelings of students and their attentiveness, attribution and goals (Gardner, 1999; Morgan, 2006). Researchers and teaching practitioners acknowledge more and more that motivation is an important quality that imbues all aspects of teaching and learning (Schunk et al., 2013: 5). The concept of motivation is applied to explain moving strength, its direction and intensity, persistence and quality of behaviour, especially the one directed to execution of certain aim (Brophy, 2015).

The most of the motivation theories defines motivation as one-dimensional phenomenon that varies on continuum from the very low to very high level. Motivation can be of

(C) Authors. Terms and conditions of Creative Commons Attribution 4.0 International (CC BY 4.0) apply. Correspondence: Ivana Bojović, Medicinska škola, Nemanjina 148, 31000 Užice, Serbia. E-mail: ivana.bojovic33@gmail.com. 
different quantity or different level of expression. At the same time, qualitative differences exist within motivation because of its complex structure and many components that make it. Individuals are not different just for the level of motivation (intensity of motivation) but for the kind or quality of motivation (Ryan \& Deci, 2000). For example, a student can be motivated to complete homework because he is curious and focused but at the same time wish to get a praise or approval by his teacher.

Scientific researches linked with motivation to learn theme illustrate problematic trend (Martin, 2009; Pajares, 2008): motivation gradually decreases during education process, particularly at transfer of a student from one educational stage to another (for example: from primary to secondary school). Research results on influence of school within the sphere of motivated learning point to large number of children who are afraid of learning, who wish to avoid learning, as well as reproducing, memorizing and discipline in school (Suzić, 2006).

When talking about motivation to learn, it is important to state series of limitations that make unrealistic expectation that all students will be motivated to learn all teaching contents of all topics, such as the following limitations: (1) attending the school is mandatory and teaching contents encompassed by the plan and program are not a choice of students, but determined by the society what students should learn; (2) teachers, at the same time, work with large group of students and cannot satisfy individual needs of each of them. As result, some students are bored, whole others can be confused or frustrated; and (3) failures of students often produce, not only personal disappointments, but public shame. Combined, the quoted factors result in focus of students on successful fulfilment of requests, and not on knowledge and skills that should be developed during activities performance, for which those had been created (Brophy, 2015). However, enhancing is the fact that we can influence motivation of students and school takes important place in such process, particularly a teacher and teaching process.

Enhancing motivation of students can be achieved by application of different activities within teaching process and specific organization of the teaching process. Different characteristics of motivation to learn among primary school students have been examined during such work. Crucial was the question whether students determine certain characteristics of teaching process as motivating or demotivating, and whether activities that motivate or demotivate are present in teaching process framework.

In the research, we used the model of motivation for learning based on the sociocognitive learning theory. The author of the model is Pintrich (2003). His concept is derived from a specific school situation and focuses on the attainment, attitudes of students about school learning, their roles and goals related to school achievement (Suzić, 2005: 2). The concept consists of five sociocognitive constructs derived from the most famous research motivations for academic achievement: perception of self-efficacy and competence belief; adaptive attribution and confidence in the ability to control; interests and intrinsic motivation, academic and social goals.

Schunk et al. (2013), after analyzing a large number of research, made systematization of factors in the teaching that can influence motivation for learning. The organization of the teaching process plays an important role, but its characteristics are also important: the process of planning the teaching process, the forms of group interaction, the quality of teaching, the representation of learning through the model, and the use of information technology in the teaching process.

The process of teaching process planning. One way to systematically incorporate overlooked procedures to encourage motivation in planning and teaching is to align this process with the TARGET program for stimulating motivation for learning created by Epstein (1992) and Ames (1988). 
Forms of group interaction. A teacher in a teaching process can form groups of students who have certain tasks. Group members perform certain activities and interact with each other. When members of the group, each performing for themselves, perform a certain activity in parallel, we are talking about coaction or individual action. Each student progresses at his own pace and his success does not depend on other students. Joint activities of members imply that there is competition (competition) or cooperation (co-operation) between them. Competitive forms of group interaction are characterized by the need to satisfy personal interests and achieve goals, dominated by struggle and prestige, and their own abilities and skills are judged in relation to competitors (Johnson \& Johnson, 2010).

Quality of teaching. Effective teaching (Rosenshine \& Stevens, 1986) analyzed the results of a large number of studies and made a review of the teaching features that make effective teaching. The researchers found that effective teaching involves the following activities: to start by briefly examining the previously learned, which is a prerequisite for learning a new one; At first, explain students the goals of time; new materials are exhibited in small steps, whereby students have the opportunity to practice every step; provide clear and detailed instructions and explanations; provide a high level of activities and exercises for all students; ask a lot of questions, check the understanding of students; guide students during initial exercise; provide clear feedback and updates; give clear instructions for time work and supervise students during the activity.

Modeling. Learning by observation is described as vicarious learning or modeling, because learning is the result of observing behaviors and the consequences of the behavior of the model in the environment. Although learning through observation depends on the availability of the model, the concept of a model can be defined very broadly. In the teaching process, the most commonly used model is determined as a teacher or other student who demonstrates certain behavior or skills.

Use of information technology. The most commonly used information technologies are used in the preparation of teaching materials, keeping records, communicating with colleagues, gathering information for preparing time, for multimedia presentations in teaching, collecting examples of good practice, for the needs of teacher research, but also for communicating with students and parents. In the last decades, special content has sites that contain a range of content to support learning, which cognitively activates students, encourages them to learn through discoveries and engage in problem solving tasks.

Rosenholtz and Simpson (1984) point out that the main aspect of the organization of the teaching process is dimensionality. One-dimensional teaching process includes several activities that are adapted to a certain level of students' abilities, and multidimensional include a wider range of activities for students with varying abilities and achievements.

\section{Method}

\subsection{Aim of research}

The aim of this research is study of motivation of students to learn in teaching process in primary school, as well as evaluation of motivation influence of certain elements of teaching process to the motivation of students.

On the basis of defined aim, the following research objectives have been defined:

(1) To examine motivation characteristics to learn of students in primary school. Students evaluate self-efficiency and own competencies, expectations of success, self-value, selfdetermination or academic control, express own attributions and convictions on ability to control (engagement, challenge, control), interest in teaching topics, evaluating level of academic progress, goals (mastery, performance goals and non-conformity). 
(2)To establish whether students determine certain characteristics of teaching process as motivating or demotivating. Students have a task to evaluate how much such activities motivate or demotivate them to learn.

(3) To establish practical pedagogic implications for teaching process on the basis of research results. It will be pointed on need to achieve in educational practice some changes that will contribute better quality of education process. Actually, there will be proposed certain steps based on results that teachers can apply in motivation incentives with students to learn within teaching process.

\subsection{Research variables}

Regarding the problem, goals and tasks of research the following variables have been chosen: (1) students' evaluation on influence of certain characteristics of teaching process on motivation to learn; (2) characteristics of motivation to learn; and (3) grade, general success in school and gender of students.

\subsection{Participants and procedure}

Selection of schools or research sample is adequate. Research includes students of fifth and eighth grades of primary school (ten primary schools in Serbia). There have participated 617 students in total. Participants were in fifth and eighth grades of primary school. The most of participants are in eighth grade (58.2\%) while percent of fifth grade students is lower (41.8\%). When talking about the sample structure per gender, it can be said that girls are in somewhat higher percent (56.9\%) comparing with boys (43.1\%). During the research realization the students have been asked information of their school success for the first half of the current school year because research has been conducted in the second half of the school year. Students have signed in an average mark for general success. The most of the percent of students have very good success (41.2\%), and the least sufficient success (0.6\%).

\subsection{Instruments}

The first instrument for students has been constructed and it contains the following:

Introduction: Controlling variables - grade, general school success and gender;

Central part contains sequence of statements relating to teaching characteristics: forms of group interaction in teaching, modeling, IT application in teaching process, organization of teaching process (statements that contain instruments for teachers adjusted to students). Five-grade scale examines whether certain characteristics of teaching process influences as motivating or demotivating to students (from completely demotivating (1) indifferent/on (3) up to completely motivating (5).

The second instrument for students is LARGE MOTIVATION INVENTORY OF ACHIEVEMENTS (VIMP). This instrument has 128 questions with YES/NO answers; and questions are divided in sub-tests. The instrument author is Suzić (2006). The instrument is designed on the basis of theoretical models of Pintrich (2003).

\section{Results}

We have used VIMP (Large inventory of motivation of achievement) to establish motivation level of students to learn which presenting an inventory on which participants answered in the form of agreement or disagreement with given statements. Participants answer to the sequence of statements with YES and NO. It is all about self-reporting which has attributive 
character. Instrument contains five sub-tests and it is designed as composite instrument so all tests together give general sum of motivation (Suzić, 2006).

First there was established a level of estimation of self-efficiency and self-evaluation of competencies with students. Obtained values are mostly closer to maximum value; therefore we can conclude that students have well developed conviction that can achieve their set goals by their own activities (7.62), high level of competencies perception (3.92) that is, they highly evaluate abilities or competencies needed to execute certain tasks. Self-determination is significantly expressed (6.45) or feeling of freedom performing activities that are interesting and important for an individual. The lowest determined level is self-respect (10.35) or evaluation of own qualities which value is slightly over one half of total sum of points. Students that evaluate their abilities in high grade will, more often than others, have better performance; they will learn more, engage more efforts and persistence on tasks solving and will be more cognitively engaged.

Table 1. Self-efficiency and competency

\begin{tabular}{|l|c|c|c|c|c|}
\hline & $\mathrm{N}$ & Minimum & Maximum & AS & SD \\
\hline Self-efficiency & 617 & 2.00 & 10.00 & 7.6240 & 1.74734 \\
\hline Perforative self-efficiency - expecting success & 617 & .00 & 10.00 & 6.2561 & 2.26476 \\
\hline Perception of competency - recognition & 617 & .00 & 5.00 & 3.9222 & 1.16236 \\
\hline Self-respect & 617 & .00 & 20.00 & 10.3517 & 4.07572 \\
\hline Self-determination - academic control & 617 & 2.00 & 10.00 & 6.4506 & 2.13457 \\
\hline I Self-efficiency and competency -IN TOTAL & 617 & 15.00 & 54.00 & 34.6045 & 7.90030 \\
\hline
\end{tabular}

When analyzing average number of points obtained for I Sub-test (total is 34.60 of $\max 55$ ), it is possible to conclude that students evaluate high level of self-efficiency and competencies. Next sub-scale contains statements relating to additive attribution and conviction of students on ability to control. This conviction is embedded in striving of an individual to feel successfully and to have control in regard to environment interacting with. In this case also, students get scores that are closer to maximum particularly when engagement of students is in question. Students evaluate that love to work on challenging tasks, and at the same time perceive high ability of control. Average number of points obtained in II Sub-test is 15.51 in total (of maximum 23).

Table 2. Adaptive attribution and conviction on ability to control

\begin{tabular}{|c|c|c|c|c|c|}
\hline & $\mathrm{N}$ & Minimum & Maximum & $\mathrm{AS}$ & SD \\
\hline Engagement & 617 & .00 & 7.00 & 5.0438 & 1.63654 \\
\hline Challenge & 617 & .00 & 8.00 & 5.0567 & 1.84858 \\
\hline Control & 617 & .00 & 8.00 & 5.4068 & 1.82732 \\
\hline $\begin{array}{l}\text { II Adaptive attribution and conviction } \\
\text { on ability to control - IN TOTAL }\end{array}$ & 617 & 2.00 & 23.00 & $\underline{15.5073}$ & 4.08597 \\
\hline
\end{tabular}

The following table points to attentiveness of students for teaching. Students show at higher grade attentiveness for teaching because in more than 60\% of cases their answers are positive. It is assumed that interest has beneficial motivational effects: curiosity linked with new extends experience and opens new possibilities. Internal motivation means self-determining spontaneous activities an individual deals with when follows freely own interests.

Table 3. Attentiveness of students for teaching and perception of competencies

\begin{tabular}{|l|c|c|c|c|c|}
\hline & $\mathrm{N}$ & Minimum & Maximum & AS & SD \\
\hline $\begin{array}{l}\text { III Attentiveness of students for teaching and } \\
\text { perception of competencies }\end{array}$ & 617 & .00 & 10.00 & $\underline{6.2674}$ & 2.02456 \\
\hline
\end{tabular}

It is important that students evaluate positively certain accomplishments, or to estimate the value of engagement in certain activity. Consequently, students will engage more efforts in the activities execution. Results point to the high level of evaluation of academic results 
(7.04). Students, to the greatest extent, accept the following statements: I go to school to study later profession I wish, to become what I wish; I go to school because I will learn there something I would never learn out of school; I go to school because there are teaching subjects I am especially interested in.

Table 4. Evaluation level for academic success

\begin{tabular}{|l|c|c|c|c|c|}
\hline & $\mathrm{N}$ & Minimum & Maximum & AS & SD \\
\hline IV Level of evaluating academic success & 617 & 1.00 & 10.00 & $\underline{7.0470}$ & 1.92372 \\
\hline
\end{tabular}

When analyzing academic goals, we can see that more distinct are goals of controlling activities and skills then performative goals. In fact, students are more directed toward development of competencies, knowledge extension and understanding through deliberate learning, than toward demonstration of skills and activities performance. In addition, significant role have social goals, bur data suggests that non-conformity is not developed sufficiently.

Students evaluate positively to great extent the following statements: I learn what teacher says that should be learned; I love when teacher plans what I will learn; I always write homework because teacher asks me to do so. The average number of points achieved in II Sub-test is 17.30 in total (of $\max 30$ ).

Table 5. Goals

\begin{tabular}{|l|c|c|c|c|c|}
\hline & $\mathrm{N}$ & Minimum & Maximum $^{1}$ & AS & SD \\
\hline Mastery goals & 617 & 1.00 & 10.00 & 7.3387 & 2.29207 \\
\hline Performative goals & 617 & .00 & 10.00 & 4.9968 & 2.24910 \\
\hline Non-conformity & 617 & 1.00 & 9.00 & 4.9676 & 1.44788 \\
\hline V Goals - IN TOTAL & 617 & 7.00 & 25.00 & $\underline{17.3031}$ & 3.15465 \\
\hline
\end{tabular}

When analyze the sum of results that have been gained individually at each sub-scale, the result is one value of controlling motivation. Data suggest that students have an average sum that is closer to maximum value, so we can conclude they are motivated to learn to significant extent and orientated toward goals of controlling (achieving).

Table 6. VIMP Test

\begin{tabular}{|l|c|c|c|c|c|}
\hline & $\mathrm{N}$ & Minimum & Maximum & AS & SD \\
\hline VIMP - IN TOTAL & 617 & 46.00 & 117.00 & $\underline{80.7293}$ & 14.73432 \\
\hline
\end{tabular}

Results should certainly be better and it is necessary to develop with students the better perception of self-efficiency, perception of competencies, and to the greatest extent selfrespect.

It has been established by the analysis of descriptive data, that boys and girls are differentiated in the level of motivation to learn measured by VIMP. Data suggest when the subscale is self-efficiency and competency is in question, the girls show higher total score and higher level of self-efficiency, estimation of competencies, self-respect and self-determination; while boys show higher level in expecting success. Girls show higher engagement, they love more challenging tasks and ability to control is better estimated than with boys. At the same time, girls show higher interest in academic achievements and evaluate it higher. In relation with boys, girls have higher scores in the sub-scale Goals. The non-conformism is only slightly higher with boys.

More descriptive statistics illustrate that almost in all sub-tests the fifth grade students expressed better achievements than eighth grade students. On the contrary to this, eighth grade students show higher conformism comparing with those in the fifth grade.

\footnotetext{
${ }^{1}$ All 3 parts of sub-test is possible to get max 10 points.
} 
T-test of independent samples displayed statistically significant differences at the level of 0.01 in achievements in VIMP Test (total of 1-28) between the fifth grade students (M (average points $)=85.50 ; \mathrm{SD}$ (standard deviation $)=14.55)$, and eighth grade $(\mathrm{M}=77.30 ; \mathrm{SD}=13.90)$. The conclusion is that students of the fifth grade achieve significantly better results at this test than eighth grade students ( 615 is df grades of freedom) $=7.085 ; \mathrm{p}=0.00$.

Illustrated differences are statistically significant with majority of sub-tests (not significant with subtests: Performative self-efficiency - expecting success; Self-determination academic control; Performative goals and Non-conformism).

Descriptive statistics measures show that students of different school success have different level of motivation to learn. There are different statistically significant differences in the level of motivation to learn between students of different school success. If we analyze total score in whole VIMP Test, based on Welch Test $\mathrm{F}=35.64, \mathrm{p}<0.01$; the conclusion is that students of different school success are statistically significantly different in achievements in all sub-tests (except with sub-tests Control and Non-conformity with no significant differences); a the level of 0.01 with sub-test Performative goals only the significances goals are at the level of 0.05. At almost all sub-scales excellent (A) students have the highest scores, and as school success is higher, the level of different aspects of motivation is higher as well.

The next task relates to student's estimation how much certain actions motivate them in teaching process. Students estimate how much tasks and activities motivate them which they have in the classroom, whether individual forms of work motivate more; cooperation or competition; to which extent actions, that are condition for efficient teaching, motivate them; are they motivated when all students work the same tasks with the same materials when evaluation is public and executed upon the same criteria; finally, are they motivated by IT application by teachers and students in teaching process.

In order to establish influence of certain characteristics of teaching process in stimulating students' motivation to learn, the students have the task to express their estimations within the Likert scale. Student evaluate the biggest motivational influence of next teaching strategies: tasks and activities for students are interesting, stimulating and diverse; teacher support autonomy of students, teaching is efficient, evaluation is formative, cooperative learning, individual work, modelling in teaching process, use of IT in teaching.

\section{Discussion}

We assumed that primary school students are partially motivated to learn. The results of the research confirmed this hypothesis. The results lead us to conclude that the students believe they can achieve their goals by self- efficacy, the students have the high level of self-perception of competences, i.e. they highly value the abilities and competences needed to perform the tasks. They also highly value self - determination i.e. the feeling of freedom while doing interesting and important activities. Self - worth, i.e. students' views of their own qualities, is least valued, just above the half of the total number of points.

As far as adaptive attributions and students' beliefs in perceived control are concerned, we conclude that students love performing challenging tasks while, at the same time, perceiving partially high perceived control. More than 50\% of the students are interested in the learning process. The results show the high level of value of academic achievements. As far as academic goals are concerned, mastery goals are more important for students than performance goals. The students are more interested in developing their competences, expanding their knowledge and understanding through deliberate learning than demonstrating the skills or performing the activities. Apart from academic goals, social goals are also important to students. However, the data show that nonconformity is not satisfactorily developed. If we add up the results of each 
subscale, we get a measure of achievement motivation. The data suggest that the students have an average score, so we can conclude that they are partially motivated to learn and achieve goals. By analyzing descriptive data, we established the gender, age and school achievement differences in student motivation to learn. The results show that not all teaching strategies are equally motivating. A large percentage of students are indifferent to certain teaching strategies. It is necessary to develop attentiveness of students for earning. Results points to high level of valuation of academic control (achievements).

Here is possible to select certain actions that stimulate students to the greatest extent and these are practical implications for teaching process. Indeed, teachers should implement the following actions that motivate students:

(1) Tasks and activities for students - interesting, stimulating and diverse tasks, activities organized by a teacher in teaching process and which help to develop learning strategy; tasks connected with former knowledge from different school subjects and experience from everyday life.

(2)Autonomy of students - organization of teaching that stimulates students to be active, teacher urge students to take initiative for own learning, teacher accept all suggestions from students for work in the classroom; and each individual students has the chance to show independence in the learning process; teachers provide students to solve the tasks in speed they like.

(3)Efficient teaching - teacher follow up with students in the classroom, carefully listen students and tries to understand their behaviour; teachers explain significances of the topic works out in the classroom as well as working goals; teacher provide examples of life situations where topics could be used as examples; teacher teach in small steps, provide detailed explanations and instructions for work and chances to students to practice all they learn during the class; students have clear and detailed instructions to solve tasks during the class with large number of questions regarding the topics to check how students truly understand the lessons; during practicing teacher gives returning information to students and correct them if making mistakes; each class, or at least ones per week, teachers provide comments on the work of students and their progress.

(4) Evaluation of teaching - teacher clearly states the mode of evaluation of students' success and progress in learning; teacher follow up with student and praise the work of each student individually when recognize the progress in learning or effort to work better; teacher follows up with the work during classes and rewards progress of a student in learning in relation to the former success and not in relation with other students in the classroom; teachers provide possibility to students to improve success and marks; teachers evaluate success of students in their work at the classroom through following up with products of their activities; evaluation is public.

(5) Cooperative learning - when students work in a group teacher allows them to talk and exchange ideas about the set task; teacher urges them to express own ideas about the task and to accept ideas of other students; urges them to cooperate during the class and to design and achieve common aim of learning and not to compete in between, one against other; formed groups are heterogeneous (different gender, interests in, etc.), all participate actively and help each other in group work; teachers give to students a task to research together with a group member certain topic and present results in the classroom.

(6) Individual work - students may have different tasks so success of one students does not depend on the other; teachers urges students to achieve own exceptional results and not to compete with others in the classroom.

(7) Modeling - teachers demonstrate different contents and skills; students demonstrate one to another different contents and skills; teacher apply models in teaching with 
visual effects allure attention of students and present to students certain contents, clearly and in small steps using schemes, illustrations, films, etc. Teachers explain to students reasons for possible mistakes in work process in order to avoid or correct them; teachers show to their students how to estimate their own knowledge ad urge them to think of own actions.

(8)IT in teaching - teachers use computer to prepare teaching materials for students.

Important finding of the research is big percent of indifferent students toward certain actions. Reasons can be various: students evaluate terribly academic achievements, have wrong image of themselves and own efficiency, if not developed interest in learning it for sure they will not recognize incentives in school.

\section{Conclusion}

Practical pedagogic implications include significant knowledge of the teaching process modes of organization that will incentive students' motivation and new strategies of urging positive motivation convictions with students. As well, this research initiated significant thoughts of teachers about their role in creation of teaching process that would urge students. The research exposed here has certain limitations. We have used self-reporting method and data we have gained by such self-reporting are often criticized in the sense of its reliability and validity. Shortages can come partially from the participants themselves, their ability to estimate own motifs, to understand reasons and causes of own behaviour. Due date for data is also in question because motives are changing permanently.

Regarding evidently confirmed importance of motivation to learn with students in teaching process, it is clear that, in connection with this concept, opens an important research field providing practical implications for our educational practice. Some ideas for further research comes from results of here illustrated research work. Further study of students' motivation to learn could be directed toward identification and other practical actions of teachers which teachers and students evaluate as the most effective in teaching process in general, and in relation with different aspects of teachers' work; and in relation with different educational and upbringing goals. Important characteristics of teaching process are not examined here and former research works confirm their impact on students' motivation to learn: social interaction teacher-student and teacher's style in managing the classroom.

In order to provide expected outcomes from group work, it is important that teachers are skilled for implementation, and trained for certain competencies. It is necessary that teachers use different forms of work and apply it in accordance with teaching context. For students is significant to be independent and to know how to cooperate and compete. Students who highly evaluate self-efficiency will employ sufficient efforts, energy and strength, or they will try and select corresponding behaviour resulting in achievement and success. Students who think they are not self-efficient probably will not even try; they will employ some insignificant efforts or will immediately give up resulting in failure and stronger conviction of own inefficiency.

It is important that teachers understand the role of attributive prejudices on students' opinion of own behaviour and abilities. At the same time, knowledge of different kinds of attribution and ways of its formation can help in information management in order to help students to form realistic attributions. In this sense, teachers should help students to learn how to attribute their success in combination of sufficient ability and employed reasonable efforts; and own failures to (temporary) lack of information or respond strategies (or insufficient efforts when this is the case); to avoid leading students toward conclusion that their failures are consequence of unchangeable limitations of abilities; attribution of success should be implied and not directly expressed, while attribution of failures of an individual should be discussed only in private. 
Teacher should actively respond to all individual capabilities of a student and develop teaching through continual cycle of observing, planning and realization of goals, tasks, methods and tools adjusted to an individual student. The critical is to build the feeling for differences in their abilities, personality characteristics, skills and experiences, interests, ambitions, as well as differences that comes from entire social context. In such way, teacher will be able to urge students to learn, to motivate them and to help in achieving short-term goals, as well as life-long learning.

\section{References}

Ames, C. (1992). Classrooms: Goals, structures, and student motivation. Journal of Educational Psychology, 84, 261-271.

Brofi Dž. ( 2015). Kako motivisati učenike da uče [How to motivate students to learn]. Clio: Beograd.

Epstein, J. L. (1988). Homework practices, achievements, and behaviors of elementary school students. Report, No. 26' Center for Research on Elementary and Middle Schools, Baltimore, MD.

Gardner, H. (1999). The disciplined mind. What all students should understand (Chapter 6). New York: Simon and Shuster.

Johnson, D., \& Johnson, R. (2010). Cooperative Learning Institute \& Interaction Book Company. Retrieved 12 August 2017 from http://www.co-operation.org/?page id=6.5.

Martin, A. (2008). Enhancing student motivation and engagement: The effects of a multidimensional intervention. Contemporary Educational Psychology, 33, 239-269.

Morgan, G. (2006). Images of organization (Chapter 4). Thousand Oaks: Sage Publications.

Pajares, F. (2008). Motivational role of self-efficacy beliefs in self-regulated learning. In: D. H. Schunk, \& B. J. Zimmerman (Eds.): Motivation and self-regulated learning. Theory, research and applications (pp. 111-141). New York, NY: Lawrence Erlbaum Associates.

Pintrich, P. R (2003). A motivational science perspective on the role of student motivation in learning and teaching contexts. Journal of Educational Psychology, 95(4), 667-686.

Rosenholtz, S. J., \& Simpson, C. (1984). Classroom organization and student stratification. The Elementary School Journal, 85, 21- 37

Ryan, R. M., \& Deci, E. L. (2000). Self-determination theory and the facilitation of intrinsic motivation, social development, and well-being. American psychologist, 55(1), 68.

Rosenshine, B., \& Stevens, R. (1986). Teaching functions. In M. C. Wittrock (Ed.): Handbook of research on teaching, 3rd ed. (pp. 376-391). New York: Macmillan.

Schunk, D. H., Pintrich, P. R., \& Meece, J. L. (2013). Motivation in education: Theory, research, and applications (4rd ed.). New Jersey: Pearson Education Inc.

Suzić, N. (2006). Mjerenje motivacije [Measurement of motivation]. Naša škola, 3-4, 88-121.

Suzić, N. (2005). Motivacija za akademsko postignuće [Motivation for academic achievement]. Podgorica: Vaspitanje i obrazovanje, 3, 59-74. 